\title{
PROPRIEDADES QUÍMICAS E MANEJ O DE SOLOS TIOMÓRFICOS DA VÁRZEA DO RIO CORURIPE, ESTADO DE ALAGOAS ${ }^{(1)}$
}

\author{
V. S. SOUZA J ÚNIOR ${ }^{(2)}$, M. R. RIBEIRO ${ }^{(3)} \&$ L. B. OLIVEIRA ${ }^{(4)}$
}

\begin{abstract}
RESUMO
Com o objetivo de estudar as propriedades químicas de solos tiomórficos da várzea do rio Coruripe, no estado de Alagoas, foram selecionados seis perfis de Gleissolos e Organossolos, na área pertencente à Usina Coruripe, onde estão estabelecidos um sistema de drenagem e a cultura da cana-de-açúcar. Os solos foram caracterizados morfologicamente, e amostras de cada horizonte foram coletadas para determinações químicas no solo e no extrato da pasta saturada, utilizando amostras na umidade de campo e secas ao ar. Foi realizado um teste de calagem em casa de vegetação com amostras compostas, representativas da área de dois perfis selecionados, nas profundidades de 0-20 e $20-40 \mathrm{~cm}$. Os resultados permitiram concluir que o maior desenvolvimento dos horizontes sulfúricos ocorreu nos solos com mais altos teores de matéria orgânica. 0 processo de secagem das amostras em laboratório promoveu a oxidação dos sulfetos e a formação de áci do sulfúrico, alterando as condições naturais dos solos no campo. A alta condutividade elétrica observada nos solos tiomórficos estudados não é indicativo de salinidade e está relacionada com a formação de ácido sulfúrico. As características químicas peculiares observadas neste estudo sugerem a realização de pesquisas sobre métodos apropriados de amostragem e análises, específicos a estes solos. Para correção do alumínio trocável dos horizontes superficiais dos solos estudados, foram necessárias doses de 11 a $25 \mathrm{t} \mathrm{ha}^{-1}$ de

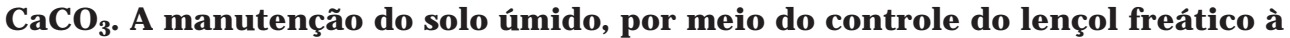
profundidade em torno de $30 \mathrm{~cm}$, éa forma mais eficiente e sustentável de controle da acidez dos solos tiomórficos, constituindo condição indispensável à utilização dos solos com cana-de-açúcar.
\end{abstract}

Termos de Indexação: Gleissolos, Organossolos, horizonte sulfúrico, cana-deaçúcar, várzeas.

(1) Parte da Tese de Mestrado do primeiro autor, apresentada ao Programa de Pós-Graduação em Agronomia - Ciência do Solo da Universidade Federal Rural de Pernambuco - UFRPE. Recebido para publicação em maio de 2000 e aprovado em abril de 2001.

(2) Engenheiro-Agrônomo, M.S. Rua Maria Vicentina da Silva 64/04. Imbiribeira. CEP 51150-570 Recife (PE). E-mail: vsouzajr@yahoo.com

(3) Professor Adjunto do Departamento de Agronomia, Área de Solos - Universidade Federal Rural de Pernambuco - UFRPE. Rua Dom Manoel de Medeiros, S/N. CEP 52171-900 Recife (PE). Bolsista do CNPq. E-mail: rosas@truenet.com.br

(4) Mestrando do Programa de Pós-graduação em Agronomia - Ciência do Solo, UFRPE. E-mail: Ibdeoliveira@yahoo.com.br 


\title{
SUMMARY: CHEMICAL PROPERTIES AND MANAGEMENT OF ACID SULFATE SOILS IN LOWLANDS OF CORURIPE RIVER VALLEY, ALAGOAS STATE, BRAZIL
}

\begin{abstract}
Sixsoil profiles wereselected in a drained lowland área at Coruripesugarmill aiming to study chemical properties of acid sulfatesoil soccurring in thefluvial plain of theCoruripe river valley, Alagoas State, Brazil. The soils were morphologically characterized and samples were taken from each horizon to determine chemical properties of soil and saturation extract, using dry and wet samples (field conditions). A greenhouse liming experiment was carried out with compound samples collected at the sites of two sel ected profiles at depths of $0-20$ and $20-40 \mathrm{~cm}$. The results showed that the greatest devel opment of sulfuric horizons was related to the highest values of organic matter. The drying procedures of the samples in laboratory resulted in sulfide oxidation and sulfuric acid formation, changing soil natural field conditions. The electrical conductivity is not necessarily an indication of salinity, and can be related to the formation of sulfuric acid. The specific chemical properties observed in this study suggest research in sampling and analytical methods for these soils. According to the liming experiment 11 to $25 \mathrm{t} \mathrm{ha}^{-1}$ of $\mathrm{CaCO}_{3}$ were necessary to neutral izesurface exchangeable aluminum. The drai nagesystem control, in order to maintain a high water table, was consi dered to bethe best management practice for sugarcane cropping in these lowland soils.
\end{abstract}

Index terms: Gleisols, Organosols, sulfuric horizon, sugarcane, lowlands.

\section{NTRODUÇÃO}

Os solos tiomórficos ou solos ácidos sulfatados caracterizam-se pela presença de horizonte sulfúrico e ou, material sulfídrico dentro de 100 am da superfície do solo, estando agrupados no Sistema Brasilei ro de Classificação de Solos (EMBRAPA, 1999) nas ordens dos Gleissolos e Organossolos.

$\mathrm{O}$ baixo $\mathrm{pH}$, menor que 3,5, característico do horizonte sulfúrico, é gerado pela oxidação de sulfetos, notadamente pirita. Estehorizontefunciona como uma barreira química ao desenvolvimento do sistema radicular das plantas, limitando o volume de solo expl orado pelas raízes e restringindo, assim, o desenvolvimento normal das plantas. É o alumínio o principal cátion trocável em sol os tiomórficos e está presente, também, na forma de hidróxidos e sulfatos básicos, sendo sua solubilidade máxima em valores de $\mathrm{pH}$ menores que 4,5 (Dent, 1986).

A utilização dos solos tiomórficos, sem o conhecimento das suas peculiaridades, tem resultado em sérios problemas à sustentabilidade dos sistemas agrícol as, princi palmente nas últimas décadas, como conseqüência da pressão populacional. Estes solos podem ser usados para agricultura, desde que sejam adotadas práticas de manejo que evitem ou, pelo menos, reduzam a acidez. Na sel eção de métodos e práticas de manejo para sol os tiomórficos, devem-se levar em conta, além do fator edáfico, outras características ambientais, como clima (quantidade e distribuição das chuvas), fatores hidrológicos (inundação, métodos de irrigação e qualidade de água) e fatores econômicos (Dent, 1986; Seiller,1992).
Existem dois processos aplicados a estes sol os que, dependendo do grau detiomorfismo, podem permitir a sua utilização agrícola. O primeiro visa minimizar a oxidação da pirita, pel o controle do regime hídrico do solo. O outro processo consiste em acelerar a oxidação da pirita e neutralizar total mente a acidez potencial. Este último, além de mais oneroso, é um processo demorado e de sustentabilidade duvidosa. O primeiro caso é o que vem sendo utilizado em algumas regiões do mundo, principalmente pelos produtores de arroz, que mantêm o solo inundado. Por outrolado, por meio do controle do nível dolençol freático em $50 \mathrm{~cm}$ de profundidade, outras culturas, a exemplo do dendê, cacau, seringueira, sorgo, batata-doce e pastagens, podem ser cultivadas (Seiler, 1992).

A várzea da Usina Coruripe, no estado deAlagoas, correspondea uma área de aproximadamente 1.800 ha, onde se encontram um sistema de drenagem ea cultura da cana-de-açúcar. A drenagem desta área sem um conhecimento mais aprofundado dos solos promoveu a formação de horizontes sulfúricos, com reflexos sobre desenvol vimento da cultura nas áreas mais afetadas.

Por se tratarem de solos pouco conhecidos, particularmente na região N ordeste, o obj etivo deste trabalho foi identificar as particularidades químicas dos solos tiomórficos da várzea do rio Coruripe, no estado de Alagoas, visando fornecer subsídios para a definição de práticas de manejo que permitam a sustentabilidade da cultura da cana-de-açúcar neles instalada. 


\section{MATERIAL E MÉTODOS}

Com base no levantamento detalhado de solos da várzea do rio Coruripe, foram selecionados seis locais para descrição e col eta dos solos, em trechos típicos das áreas com tiomorfismo, eabrangendo seis diferentes dasses de sol os tiomórficos: GleissoloTiomórfico Hísticotípicoálico; GleissoloTiomórfico Húmicotípico distrófico; Organossol o Tiomórfico Sáprico térrico distrófico; Organossolo TiomórficoSápricotérricoálico; Organossolo Tiomórfico Hêmico térrico álico e Organossol o Tiomórfico Hêmico térrico distrófico.

A descrição dos perfis e a coleta das amostras para as análises de caracterização foram feitas segundo as recomendações do Manual de Descrição e Col eta de Solo no Campo (Lemos \& Santos, 1996).

As amostras deformadas foram pré-tratadas, secas ao ar, destorroadas e passadas em peneira de $2 \mathrm{~mm}$, para a obtenção da TFSA e separação da fração grosseira. Foram também utilizadas amostras com umidade de campo (ACUC) na realização de al gumas das análises químicas, visando aquilatar a influência do método analítico na modificação das condições naturais dos solos.

As análises químicas foram realizadas na TFSA eem ACUC. As daTFSA incluíram as determinações de: $\mathrm{pH}$ (em água e $\mathrm{KCl}$, na proporção de 1:1 e 1:2,5 na base de volume), complexo sortivo, fósforo disponível, carbono orgânico, nitrogênio total e enxofretotal. Foram utilizados os métodos propostos pela EMBRAPA (1997), com exceção do carbono orgânico, que foi determinado por via úmida, utilizando o método proposto por Snyder \& Trofynow (1984), e por combustão, via seca a 375으, conforme método citado por Dent (1986). No extrato da pasta desaturação, foram determi nados $\mathrm{pH}$, condutividade elétrica, cátions eânions solúveis. Na determinação dos cátions solúveis, seguiram-se os métodos propostos pela EMBRAPA (1997). Na determinação dos ânions, foram usados os seguintes métodos: cloretos, por titulação potenciométrica, de acordo com Adriano \& Doner (1982); bicarbonatos, por titulação com ácido sulfúrico, esulfatos, por col orimetria, pela reação com o cromato de bário, com liberação do íon cromato, de cor amarela, em quantidade proporcional à de íons sulfato, de acor do com método descrito por Dewis \& Freitas (1970).

Nas amostras com umidade de campo (ACUC), foram determinados $\mathrm{pH}$, condutividade elétrica do extrato da pasta de saturação, cátions e ânions solúveis.

As análises foram realizadas nos laboratórios de química e fertilidade de sol os da UFRPE, com duas repetições para cada amostra.

A pós a caracterização química, foram sel ecionados dois perfis deacordo com os maiores teores de H +Al, sendo um Gleissolo Tiomórfico e um Organossolo Tiomórfico, visando à real ização de teste de cal agem.
As amostras foram col etadas nas profundidades de $0-20$ e $20-40 \mathrm{~cm}$, e, depois de secas ao ar, foram destorroadas e passadas em peneira de $2 \mathrm{~mm}$. As amostras (500 g) foram incubadas com carbonato de cál cio e carbonato de magnésio com relação 3:1, seguindo recomendação de calagem baseada na neutralização do $\mathrm{H}+\mathrm{Al}$. Este experimento foi feito em casa de vegetação em del ineamento inteiramente ao acaso, com arranjo fatorial $2 \times 5 \times 2$, tendo sido utilizados dois sol os, cinco doses de cal cário $(0 ; 0,25$; 0,5; 1 e 2, vezes a dose recomendada de carbonato de cálcio), duas profundidades de coleta (0-20 e 20$40 \mathrm{~cm}$ ) e três repetições.

Após a montagem do experimento, foram realizadas análises quinzenais para determinar o $\mathrm{pH}$ emágua eKCl 1 mol L-1. A umidadedas amostras foi mantida próxima à capacidade de campo. Aos 60 dias, fez-se a última amostragem para determinação de $\mathrm{pH}, \mathrm{H}+\mathrm{Al}$ e $\mathrm{Al}^{3+}$. Esses dados foram utilizados nas análises de regressão, visando determinar a melhor equação que representasse o comportamento desses solos com relação às doses de carbonato de cálcio aplicadas.

\section{RESULTADOS E DISCUSSÃO}

\section{Propriedades químicas}

\section{Carbono orgânico, nitrogênio total e relação $\mathbf{C} / \mathbf{N}$}

A determinação de carbono orgânico (Quadro 1), foi realizada pelo método citado por Snyder \& Trofynow (1984). Os valores obtidos por este método, entretanto, não foram condizentes com as características morfológicas dos sol os estudados. Por estemotivo, foi feita a determi nação direta da matéria orgânica, via combustão seca, conforme método citado por Dent (1986), que afirma ser a oxidação com dicromato inadequada para solos com sulfetos pelo fato deo dicromato reagir com a pirita, subestimando os resultados. Os valores obtidos por este método apresentaram-se coerentes com as características morfológicas dos solos, principalmente textura e consistência, razão por que foram considerados neste estudo.

Os Gleissolos estudados apresentaram valores elevados de carbono orgânico (Quadro 1). Nos Gleissolos, esses teores variaram de 44,02 a $109,68 \mathrm{~g} \mathrm{~kg}^{-1}$, tendo o perfil 1 apresentado o valor mais alto, o que motivou o enquadramento do seu horizontesuperficial noconceito dehorizonte hístico. Os Organossolos apresentaram teores de carbono orgânico com valores ao longo dos perfis variando de 32,42 a 445,85 $\mathrm{g} \mathrm{kg}^{-1}$.

Os altos teores de carbono orgânico são uma característica muito importante, do ponto de vista 
Quadro 1. Carbono orgânico, nitrogênio total e relação carbono/nitrogênio dos solos estudados

\begin{tabular}{|c|c|c|c|c|c|}
\hline \multirow{2}{*}{ Horizonte } & \multirow{2}{*}{ Profundidade } & \multicolumn{2}{|c|}{ C orgânico } & \multirow{2}{*}{ N-total } & \multirow{2}{*}{$\mathbf{C} / \mathbf{N}$} \\
\hline & & Úmida & Seca & & \\
\hline \multicolumn{6}{|c|}{$\mathrm{cm}$} \\
\hline \multicolumn{6}{|c|}{ Perfil 1 - Gleissolo Tiomórfico Hístico típico álico } \\
\hline $\begin{array}{l}\mathrm{Hp} \\
2 \mathrm{Cq}\end{array}$ & $\begin{array}{r}0-30 \\
30-55\end{array}$ & $\begin{array}{l}78,20 \\
63,61\end{array}$ & $\begin{array}{r}109,68 \\
88,03\end{array}$ & $\begin{array}{l}8,48 \\
6,19\end{array}$ & $\begin{array}{l}12,9 \\
14,2\end{array}$ \\
\hline $3 C g j$ & $55-95+$ & 29,21 & 44,02 & 2,45 & 17,9 \\
\hline \multicolumn{6}{|c|}{ Perfil 2 - Gleissolo Tiomórfico Húmico típico distrófico } \\
\hline Ap & $0-20$ & 55,75 & 88,46 & 7,30 & 12,1 \\
\hline $\mathrm{ACg}$ & $20-45$ & 55,24 & 87,57 & 6,96 & 12,6 \\
\hline $2 \mathrm{Cg}$ & $45-90$ & 57,43 & 82,43 & 8,53 & 9,6 \\
\hline 3Cgj & $90-120+$ & 61,83 & 96,58 & 4,44 & 21,7 \\
\hline \multicolumn{6}{|c|}{ Perfil 3 - Organossolo Tiomórfico Sáprico térrico distrófico } \\
\hline $\mathrm{Hdp}$ & $0-14$ & 107,74 & 148,23 & 10,57 & 14,0 \\
\hline Hdo & $14-43$ & 70,18 & 140,40 & 9,91 & 14,2 \\
\hline $4 \mathrm{Cgj}$ & $75-130+$ & 37,74 & 58,25 & 9,30 & 6,3 \\
\hline \multicolumn{6}{|c|}{ Perfil 4 - Organossolo Tiomórfico Sáprico térrico álico } \\
\hline $\mathrm{Hdp}$ & $0-16$ & 156,08 & 237,79 & 10,56 & 14,4 \\
\hline Hdoj & $16-33$ & 184,03 & 283,99 & 16,13 & 17,6 \\
\hline $\mathrm{Hdj}$ & $33-50$ & 91,40 & 122,16 & 7,13 & 17,1 \\
\hline $4 \mathrm{Cgj}{ }_{1}$ & $50-80$ & 32,76 & 44,39 & 3,23 & 13,7 \\
\hline $4 \mathrm{Cgj} 2$ & $80-140+$ & 16,70 & 32,42 & 2,51 & 12,9 \\
\hline \multicolumn{6}{|c|}{ Perfil 5 - Organossolo Tiomórfico Hêmico térrico álico } \\
\hline $\mathrm{Hdp}$ & $0-18$ & 81,45 & 260,41 & 15,16 & 17,2 \\
\hline 2H doj & $18-45$ & 133,94 & 346,57 & 13,83 & 25,1 \\
\hline $3 \mathrm{Cgj}$ & $45-147+$ & 28,80 & 69,22 & 1,75 & 39,6 \\
\hline \multicolumn{6}{|c|}{ Perfil 6 - Organossolo Tiomórfico Hêmico térrico distrófico } \\
\hline Hop & $0-15$ & 138,19 & 236,77 & 30,18 & 7,8 \\
\hline $2 \mathrm{H}$ doj & $15-75$ & 221,51 & 445,85 & 17,96 & 24,8 \\
\hline $3 \mathrm{Cgj}$ & 75-142+ & 39,63 & 47,39 & 3,26 & 14,6 \\
\hline
\end{tabular}

da gênese dos solos tiomórficos, coincidindo os mais al tos teores com o desenvol vimento mais pronunciado do horizonte sulfúrico, caracterizado pelos valores mais baixos de $\mathrm{pH}$ e maiores teores de sulfato solúvel (Quadros 2 e 4), confirmando a afirmação de van Breemen (1962), citado por Seiler (1992), de que a disponibilidade de substâncias orgânicas é o fator mais importante na formação de sol os tiomórficos.

Os teores de nitrogênio são el evados ao longo dos perfis estudados e compatíveis com os altos teores de matéria orgânica. Os teores de nitrogênio total variaram de 1,75 a 30,18 $\mathrm{g} \mathrm{kg}^{-1}$, correspondendo os mai ores val ores às camadas orgâni cas esuperficiais, variando de 8,46 a 30,18 $\mathrm{g} \mathrm{kg}^{-1}$ de solo (Quadro 1).

Avaliando os resultados da relação $\mathrm{C} / \mathrm{N}$, observouse que os solos estudados apresentaram relação $\mathrm{C} / \mathrm{N}$ baixa, considerando que para sol os com alto teor de carbono orgânico e condições hidromórficas eram esperadas relações superiores a 20 (Brady, 1989). Os resultados encontrados variaram de 6,3 a 39,6, ressalvando-se que esses valores, em sua maioria, foram menores que 20. Os resultados encontrados diferiram dos de Lani (1998), que, estudando Organossolos e Gleissolos, ambos tiomórficos, no Espírito Santo, encontrou resultados superiores.

\section{pH, alumínio trocável e saturação por alumínio}

No quadro 2, encontram-se os valores de $\mathrm{pH}$ em água e em $\mathrm{KCl}$. A reação do sol o ao longo de todos os perfis variou de extremamente ácida a fortemente ácida, de acordo com a EMBRAPA (1999), em ambas as rel ações sol o:água ou $\mathrm{KCl}$, nas análises real izadas com o solo na umidade de campo e nas amostras secas.

Os resultados mostraram diferenças mínimas nos val ores do $\mathrm{pH}$ aferidos nas relações sol o:água ou $\mathrm{KCl}$ de 1:1 e 1:2,5, mostrando que a relação 1:2,5 (v/v), recomendada pela EMBRAPA (1997) para sol os nãotiomórficos, podetambém ser utilizada na determinação de pH de solos tiomórficos. 
Não foi possível a determinação do pH em água na proporção 1:1, na base demassa, como recomendado pela EMBRAPA (1999) para solos tiomórficos. Os horizontes orgânicos, em virtude da baixa densidade global e alta capacidade de retenção de água, não formaram suspensão, quandoa proporção foi feita na base de massa. Por esta razão, neste trabal ho, foram adotadas as relações solo: água 1:1 e 1:2,5 na base de volume, como recomendado para sol os não-tiomórficos.

Considerando o pH em água 1:2,5 (v/v), seus valores ficaram entre 2,3 e 4,8, ao longo dos perfis, com os maiores valores nos horizontes superficiais não-sulfúricos, entre 3,7 e 4,8. Os horizontes sulfúricos, caracterizados pelo $\mathrm{pH} \leq 3,5$, apresentaram valores no intervalo de 2,3 a 3,3. Esses valores de $\mathrm{pH}$ ao longo dos perfis foram semelhantes aos encontrados por Alves (1997) em Organossolos Tiomórficos da região de Campos (RJ ), e mais altos que os observados por Lani (1998) em Organossolos e Gleissolos, ambos tiomórficos, no delta do rio Itapemirim no Espírito Santo.
Observou-se diferença expressiva do $\mathrm{pH}$ emágua $(1: 2,5)$, determinado em ACUC eTFSA. Os valores observados nas amostras úmidas foram sempre iguais ou superiores aos valores obtidos com as amostras secas. As maiores diferenças foram observadas nos Organossol os e nas camadas mais profundas e mais encharcadas, menos sujeitas ao processo de sulfurização provocado pela drenagem. Foram observadas diferenças entre 0,1 e 1,8 unidades de $\mathrm{pH}$, dependendo do grau de tiomorfismo e do nível de umidade das amostras no campo. Resultados semel hantes foram encontrados por Kanapathy (1973), em sol os tiomórficos da Malásia.

Os teores de alumínio trocável encontrados ao longo dos perfis variaram de 6,5 a $81,5 \mathrm{cmol}_{\mathrm{C}} \mathrm{kg}^{-1}$, coincidindo os maiores valores com os horizontes sulfúricos, para todos os solos, com exceção do horizonte 3 Cgj do perfil 1 (Quadro 3). Esses valores ultrapassaram olimite superior tolerável à maioria das plantas cultivadas que, deacordo com Malavolta (1980), é de $0,5 \mathrm{cmol}_{\mathrm{c}} \mathrm{kg}^{-1}$ de solo. No entanto, como

Quadro 2. Valores de pH dos solos em terra fina seca ao ar (TFSA) e em amostras com umi dade de campo (ACUC)

\begin{tabular}{|c|c|c|c|c|c|c|c|}
\hline \multirow{3}{*}{ Horizonte } & \multirow{3}{*}{ Profundidade } & \multicolumn{4}{|c|}{ TFSA } & \multicolumn{2}{|c|}{ ACUC } \\
\hline & & $\mathrm{H}_{2} \mathrm{O}$ & $\mathbf{K C l}$ & $\mathrm{H}_{2} \mathrm{O}$ & $\mathbf{K C l}$ & $\mathrm{H}_{2} \mathrm{O}$ & $\mathbf{K C l}$ \\
\hline & & \multicolumn{2}{|c|}{$1: 2,5$} & \multicolumn{2}{|c|}{ 1:1 } & \multicolumn{2}{|c|}{$1: 2,5^{(1)}$} \\
\hline \multicolumn{8}{|c|}{ Perfil 1 - Gleissolo Tiomórfico Hístico típico álico } \\
\hline $\begin{array}{l}\mathrm{Hp} \\
2 \mathrm{Cg} \\
3 \mathrm{Cgj}\end{array}$ & $\begin{array}{c}0-30 \\
30-55 \\
55-95+\end{array}$ & $\begin{array}{l}4,0 \\
3,8 \\
3,3\end{array}$ & $\begin{array}{l}3,7 \\
3,5 \\
3,1\end{array}$ & $\begin{array}{l}4,0 \\
3,7 \\
3,2\end{array}$ & $\begin{array}{l}3,5 \\
3,4 \\
2,9\end{array}$ & $\begin{array}{l}4,1 \\
3,9 \\
3,4\end{array}$ & $\begin{array}{l}3,7 \\
3,5 \\
3,0\end{array}$ \\
\hline \multicolumn{8}{|c|}{ Perfil 2 - Gleissolo Tiomórfico Húmico típico distrófico } \\
\hline $\begin{array}{l}\mathrm{Ap} \\
\mathrm{ACg} \\
2 \mathrm{Cg} \\
3 \mathrm{Cgj}\end{array}$ & $\begin{array}{l}0-20 \\
20-45 \\
45-90 \\
90-120+\end{array}$ & $\begin{array}{l}4,6 \\
4,8 \\
4,0 \\
2,5\end{array}$ & $\begin{array}{l}4,0 \\
3,9 \\
3,4 \\
2,6\end{array}$ & $\begin{array}{l}4,5 \\
4,6 \\
3,9 \\
2,7\end{array}$ & $\begin{array}{l}3,9 \\
3,8 \\
3,3 \\
2,5\end{array}$ & $\begin{array}{l}4,9 \\
5,0 \\
4,2 \\
2,5\end{array}$ & $\begin{array}{l}3,9 \\
3,9 \\
3,4 \\
2,6\end{array}$ \\
\hline \multicolumn{8}{|c|}{ Perfil 3 - Organossolo Tiomórfico Sáprico térrico distrófico } \\
\hline $\begin{array}{l}\text { Hdp } \\
\text { Hdo } \\
4 \text { Cgj }\end{array}$ & $\begin{array}{l}0-14 \\
14-43 \\
75-130+\end{array}$ & $\begin{array}{l}4,0 \\
4,1 \\
2,3\end{array}$ & $\begin{array}{l}3,7 \\
3,7 \\
2,5\end{array}$ & $\begin{array}{l}3,9 \\
4,0 \\
2,6\end{array}$ & $\begin{array}{l}3,6 \\
3,6 \\
2,3\end{array}$ & $\begin{array}{l}4,1 \\
4,2 \\
4,1\end{array}$ & $\begin{array}{l}3,7 \\
3,7 \\
2,5\end{array}$ \\
\hline \multicolumn{8}{|c|}{ Perfil 4 - Organossolo Tiomórfico Sáprico térrico álico } \\
\hline $\begin{array}{l}\text { Hdp } \\
\text { Hdoj } \\
\text { Hdj } \\
4 C j_{1} \\
4 C g j_{2}\end{array}$ & $\begin{array}{l}0-16 \\
16-33 \\
33-50 \\
50-80 \\
80-140+\end{array}$ & $\begin{array}{l}3,9 \\
3,3 \\
2,5 \\
2,6 \\
2,9\end{array}$ & $\begin{array}{l}3,8 \\
3,3 \\
2,5 \\
2,7 \\
3,0\end{array}$ & $\begin{array}{l}3,9 \\
3,2 \\
2,5 \\
2,8 \\
3,3\end{array}$ & $\begin{array}{l}3,7 \\
3,2 \\
2,4 \\
2,5 \\
2,9\end{array}$ & $\begin{array}{l}4,0 \\
3,5 \\
2,5 \\
2,9 \\
3,8\end{array}$ & $\begin{array}{l}3,8 \\
3,4 \\
2,3 \\
2,3 \\
3,2\end{array}$ \\
\hline \multicolumn{8}{|c|}{ Perfil 5 - Organossolo Tiomórfico Hêmico térrico álico } \\
\hline $\begin{array}{l}\mathrm{Hdp} \\
2 \mathrm{Hdoj} \\
3 \mathrm{Cgj}\end{array}$ & $\begin{array}{l}0-18 \\
18-45 \\
45-147+\end{array}$ & $\begin{array}{l}3,7 \\
3,1 \\
2,5\end{array}$ & $\begin{array}{l}3,5 \\
3,0 \\
2,7\end{array}$ & $\begin{array}{l}3,6 \\
3,0 \\
2,8\end{array}$ & $\begin{array}{l}3,5 \\
3,0 \\
2,5\end{array}$ & $\begin{array}{l}3,7 \\
3,3 \\
3,5\end{array}$ & $\begin{array}{l}3,6 \\
3,1 \\
2,7\end{array}$ \\
\hline \multicolumn{8}{|c|}{ Perfil 6 - Organossolo Tiomórfico Hêmico térrico distrófico } \\
\hline $\begin{array}{l}\text { Hop } \\
2 \mathrm{Hdoj} \\
3 \mathrm{Cgj}\end{array}$ & $\begin{array}{l}0-15 \\
15-75 \\
75-142+\end{array}$ & $\begin{array}{l}4,1 \\
3,1 \\
2,7\end{array}$ & $\begin{array}{l}4,0 \\
3,0 \\
3,0\end{array}$ & $\begin{array}{l}4,0 \\
3,0 \\
3,0\end{array}$ & $\begin{array}{l}3,8 \\
2,9 \\
2,7\end{array}$ & $\begin{array}{l}4,3 \\
3,4 \\
3,3\end{array}$ & $\begin{array}{l}3,9 \\
3,1 \\
3,0\end{array}$ \\
\hline
\end{tabular}

(1) Relação na base de volume. 
são solos com altos teores de matéria orgânica, o alumínio pode estar, em parte, formando compl exos com a matéria orgânica, de forma estável, podendo, assim, não causar problemas de toxidez às culturas mais tolerantes (Andriesse, 1984). Os valores encontrados são compatíveis com os de outros sol os tiomórficos, como os estudados por Lani (1998).

Quanto à saturação por alumínio, os resultados mostram os val ores variando de 12 a 86\% (Quadro 3). Os perfis um, quatro e cinco foram os que apresentaram os mai ores valores, classificando-se como álicos, de acordo com EMBRAPA (1999). Esses resultados foram compatíveis com os encontrados por Lani (1998).

\section{Bases trocáveis, saturação por bases e capacidade de troca de cátions}

O complexo sortivo dos solos estudados apresentou o magnésio como cátion dominanteentre as bases de troca, com valores variando de 1,4 a $25,7 \mathrm{cmol}_{\mathrm{C} \mathrm{kg}} \mathrm{kg}^{-1}$, ocorrendo as mai ores concentrações nos horizontes inferiores e não-orgânicos de todos os perfis (Quadro 3).
O cál cio foi o segundo cátion dominante entre as bases trocáveis com valores variando ao longo dos perfis de 10,5 a 0,6 $\mathrm{cmol}_{\mathrm{c}} \mathrm{kg}^{-1}$, apresentando as maiores concentrações nos horizontes superiores dos perfis 1, 2, 4 e 6, com valores de 2,7, 10,5, 9,5 e $10,2 \mathrm{cmol}_{\mathrm{c}} \mathrm{kg}^{-1}$, respectivamente. O contrário ocorreu nos perfis 3 e 5, onde a superfície apresentou os menores valores, que foram de 7,4 e 2,6 $\mathrm{cmol}_{\mathrm{c}} \mathrm{kg}^{-1}$, respectivamente (Quadro 3). As maiores concentrações de cál cio na superfícieforam, provavel mente, resultantes da aplicação de calcário nos solos, em consonância com seu histórico de uso.

Os resultados referentes à concentração de magnésioe de cál ci o foram di ferentes dos observados por Lani (1998) e por Conceição (1989) que encontraram o cál cio como cátion dominante entre as bases detroca, eo magnésio como segundo el emento dominante. Os valores encontrados para o cálcio foram semelhantes, porém os valores do magnésio foram bem inferiores aos observados nos perfis da várzea do rio Coruripe. A diferença observada entre os sol os da várzea do rio Coruripe eos sol os estudados por Conceição (1989) e Lani (1998) podeser atribuída

Quadro 3. Complexo sortivo; saturação por bases, alumínio e sódio; enxofre total e fósforo extraível dos solos

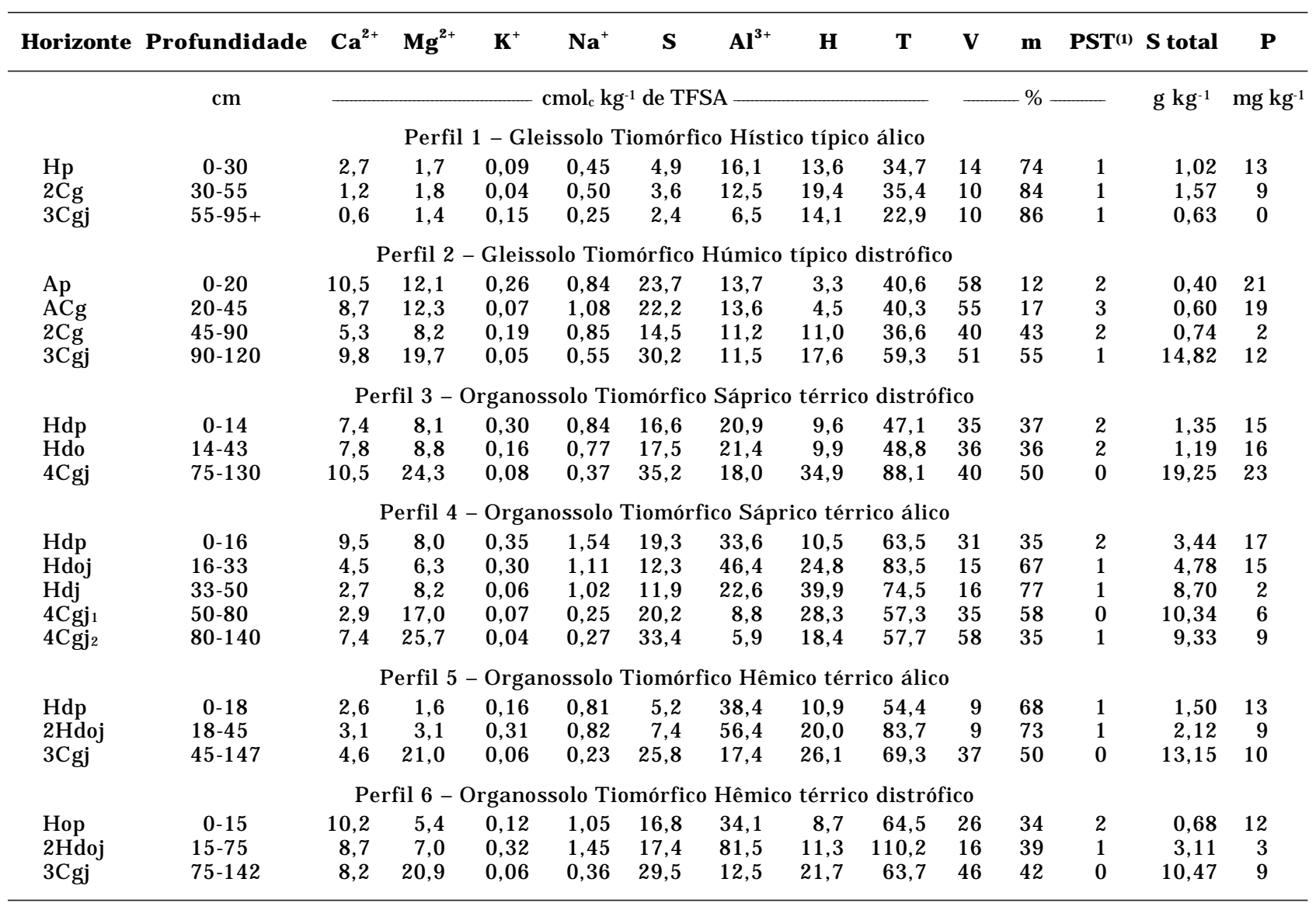

(1) Percentagem de sódio trocável. 
à natureza dos materiais transportados pelo rio Coruripe, provenientes das áreas do alto curso, trecho do semi-árido onde predomina uma associação de Planossol os Solódicos e Neossol os L itólicos, desenvolvidos de rochas cristalinas equeapresentam omagné sio como cátion dominante no complexo sortivo.

Os teores de potássio trocável nos horizontes superficiais dos sol os estudados apresentaram-se de médios a altos, com os valores entre 0,12 e $0,45 \mathrm{cmol}_{\mathrm{C}} \mathrm{kg}^{-1}$, exceto no perfil 1, que apresentou val or de $0,09 \mathrm{cmol}_{\mathrm{C}} \mathrm{kg}^{-1}$, considerado baixo, segundo recomendação de adubação do estado de Alagoas, citada por Malavolta (1992). Os teores de potássio decresceram com a profundidade, apresentando valores baixos nos horizontes mais profundos, com variações entre 0,04 e 0,08 $\mathrm{cmol}_{\mathrm{c}} \mathrm{kg}^{-1}$.

O sódio trocável apresentou, ao longo dos perfis, valores entre 0,2 e $1,5 \mathrm{cmol}_{\mathrm{c}} \mathrm{kg}^{-1}$, com os maiores teores ocorrendo nos horizontes superficiais. Constatou-se mai or concentração deste el emento ao longo dos perfis em relação ao potássio; no entanto, o sódio não constitui um problema, visto que sua saturação no complexo sortivo atingiu o valor máximo de $3 \%$.

A soma de bases (Quadro 3) tende a aumentar em profundidade nos perfis 3, 5 e 6 , onde os valores variaram de 5,2 a $35,2 \mathrm{cmol}_{\mathrm{c}} \mathrm{kg}^{-1}$, podendo-se observar uma relação inversa com o pH, contrariamenteao que écitado na literatura: a soma de bases el eva-se com o aumento do pH (Raij, 1991). Este fato parece ser determinado pelo aumento do magnésio com a profundidade, bem como pelos el evados teores deal umínio trocável contribuindo para a acidez. Nos perfis 1 e 4, a variação na soma de bases ocorreu de forma diretamente proporcional à variação do $\mathrm{pH}$, ou seja, à medida que este decrescia, a soma de bases decrescia também. Os valores variaram de 2,4 a $33,4 \mathrm{cmol}_{\mathrm{c}} \mathrm{kg}^{-1}$ de solo.

A saturação por bases mostrou resultados bem variados ao longo dos perfis estudados, evidenciandose, porém, o caráter distrófico de todos os perfis, com val ores de saturação por bases entre 9 e $46 \%$. Apenas os dois primeiros horizontes do perfil 2 apresentaram valores de 58 e $55 \%$, respectivamente, possivelmente em decorrência da adição de corretivos.

A CTC dos solos apresentou val ores muito altos, o que já era esperado em virtude dos altos teores de matéria orgânica destes solos. Esta elevada CTC deveu-se, principalmente, à presença dos colóides orgânicos, que possuem grande superfície específica (Brady, 1989). Segundo os resultados do quadro 3, os Organossolos apresentaram os maiores valores de CTC, que variaram de 47,1 a 110,2 $\mathrm{cmol}_{\mathrm{C}} \mathrm{kg}^{-1}$, enquanto os Gleissolos apresentaram valores entre 22,9 e 79,2 $\mathrm{cmol}_{\mathrm{C}} \mathrm{kg}^{-1}$. Resultados semel hantes foram encontrados por Lani (1998) em Organossolos Tiomórficos e Gleissol os Tiomórficos, e por Conceição (1989) em Organossol os não-Tiomórficos.

\section{Fósforo extraível}

As maiores concentrações de fósforo ocorreram nos horizontes superficiais, em todos os perfis, exceto no perfil 3, onde a maior concentração foi no horizonte subsuperficial (4 Cgj) (Quadro 3). Os valores deste elemento nos horizontes superficiais variaram de 13 a $21 \mathrm{mg} \mathrm{kg}^{-1}$. De acordo com Malavol ta (1992), valores superiores a $16 \mathrm{mg} \mathrm{kg}^{-1}$ são considerados elevados para o estado de Alagoas, neste grupo se enquadrando os perfis 2 e 4 . Valores entre 6 e $16 \mathrm{mg} \mathrm{kg}^{-1}$ observados nos demais perfis são considerados médios. As mai ores concentrações do fósforo na superfície podem ser resultantes dos maiores valores de $\mathrm{pH}$ apresentados por estes horizontes, ou resultantes da adição de corretivos e fertilizantes, por se tratar de área intensamente cultivada. É importantesalientar queos altos valores encontrados para o fósforo ou para qualquer outro nutriente podem ser uma conseqüência da baixa densidade global, podendo apresentar valores diferentes se os resultados forem expressos em volume. A baixa densidade gl obal dos solos orgânicos deve, portanto, ser levada em consideração quando da interpretação de resultados analíticos para comparação com solos de maior densidade.

\section{Enxofre total e pasta saturada}

Os teores de enxofre total variaram de 0,40 a $19,25 \mathrm{~g} \mathrm{~kg}^{-1}$ (Quadro 3). O enxofretotal, isoladamente, não se mostrou critério eficiente na distinção dos horizontes sulfúricos (e, ou, material sulfídrico), uma vez que os horizontes $3 \mathrm{Cgj}$ do perfil 1, Hdoj do prefil 4 e $2 \mathrm{H}$ dj dos perfis 5 e 6 não apresentaram os teores mínimos de 7,5 $\mathrm{g} \mathrm{kg}^{-1}$ requeridos para tal, conforme critério citado por Oliveira et al. (1992).

Já os teores de sulfato solúvel no extrato da pasta saturada foram, nos horizontes sulfúricos, superiores a $500 \mathrm{mg} \mathrm{kg}^{-1}$, conforme critério da EMBRAPA (1999). Todavia, al guns horizontes não-Tiomórficos também apresentaram teores de sulfato superiores ao especificado (Quadro 4).

Analisando os resultados, observou-se que os val ores deC.E. na ACUC foram baixos, praticamente ao longo de todos os perfis, tendo como referência o valor de 4,0 dS m-1 (E MBRAPA, 1999). Comparando estes valores com os obtidos na TFSA, constatou-se um incremento bastante sensível nos val ores da C.E. nos horizontes sulfúricos. Os valores nas amostras com umidade de campo variaram de 0,69 a $5,68 \mathrm{dS} \mathrm{m}^{-1}$, ao passo que, nas amostras secas, a variação foi de 0,82 a 16,2 dS $\mathrm{m}^{-1}$.

O aumento na condutividade elétrica nas amostras secas ao ar vem demonstrar que o processo de secagem das amostras desencadeou o processo de sulfurização, alterando as condições naturais do solo no campo, além de demonstrar que os altos valores da condutividade elétrica dos horizontes sulfúricos dos perfis estudados não estão relacionados com a salinidade, mas, sim, com os íons 
hidrogênio e sulfato, liberados na solução pela oxidação da pirita, com formação de ácido sulfúrico. Esta afirmação é corroborada pelas correlações significativas entre condutividade elétrica e os teores de sulfato, hidrogênio e pH (Figura 1).

Em se tratando de solos tiomórficos, a condutividade el étrica el evada não pode ser usada, portanto, como único critério para identificação da salinidade.

Pelo que foi discutido, os solos da várzea do rio Cururipenão apresentaram sal ini dade el evada como era esperado em sol os que na sua formação sofreram influência da água do mar. Isto pode ser explicado pel o fato de, nas condições atuais de altura do nível do mar, a área não sofrer mais influência das marés e ter sido submetida a um processo de lavagem pelo fluxo de água proveniente do sopé dos tabuleiros
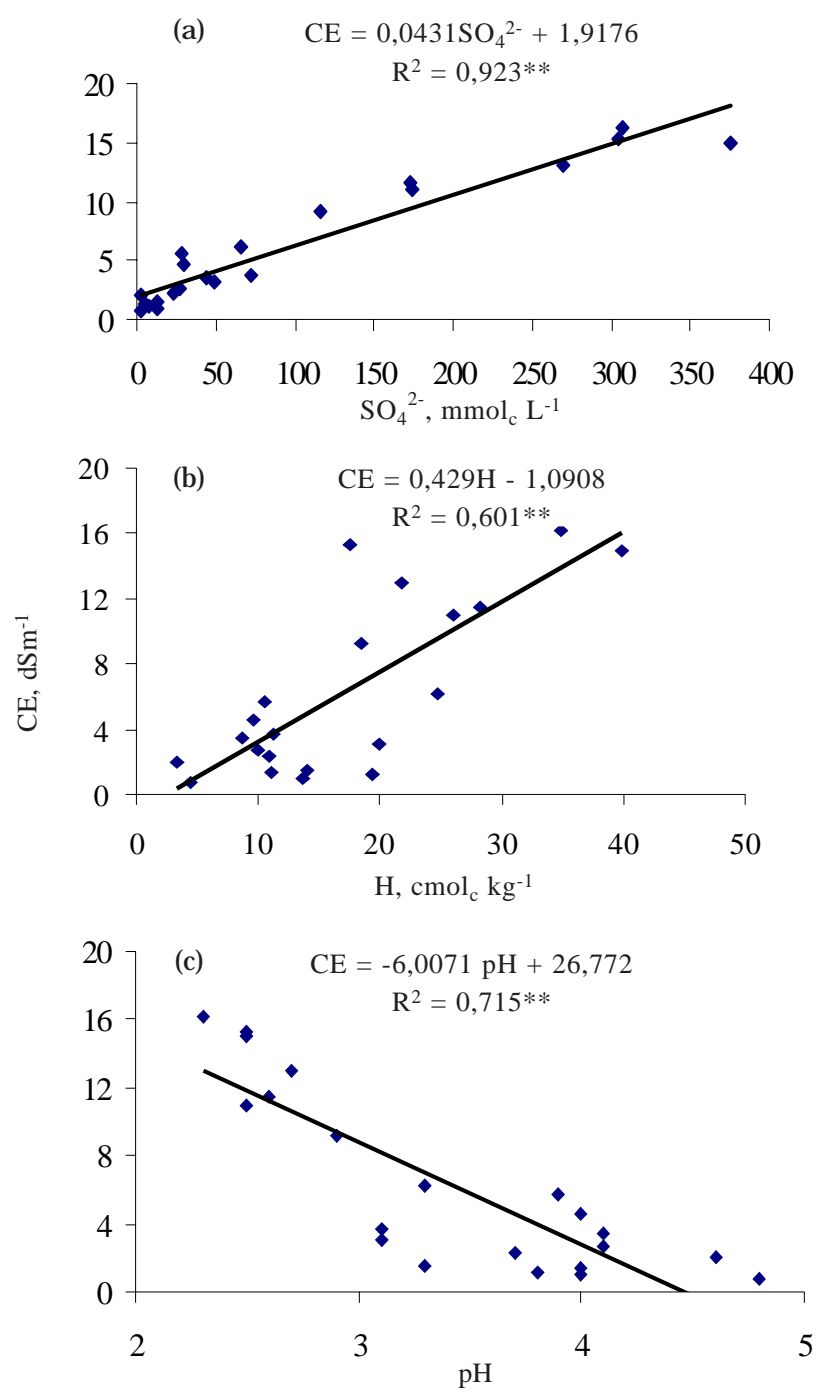

Figura 1. Correlações entre condutividade elétrica e sulfato solúvel (a); condutividade elétrica e hidrogênio trocável (b), condutividade elétrica e pH (c). costei ros que margeiam a várzea e que comandam a alimentação do lençol freático (Souza J r., 1999). Segundo Dent (1986), em áreas de sol os tiomórficos permeáveis, os sais podem ser facilmentelixiviados pelas águas pluviais ou por inundação com água de boa qualidade.

O quadro 4 apresenta as concentrações dos ânions no extrato de saturação. As concentrações de sulfatos nas amostras nas condições de campo apresentaram val ores entre 3,75 e 98,48 $\mathrm{mmol}_{\mathrm{C}} \mathrm{L}^{-1}$, enquanto, nas amostras secas, os valores variaram de 2,25 a $375,28 \mathrm{mmol}_{\mathrm{C}} \mathrm{L}^{-1}$. As concentrações de doretos e bicarbonatos não apresentaram diferenças expressivas entreas duas determinações. Os teores, em geral, variaram de 0,0 a $11,3 \mathrm{mmol}_{\mathrm{C}} \mathrm{L}^{-1}$ e de 0,0 a $0,50 \mathrm{mmol}_{\mathrm{C}} \mathrm{L}^{-1}$, respectivamente, para os íons cloreto e bicarbonato.

Analisando, ainda, o ânion sulfato, observou-se uma concentração extremamente superior desse ânion em relação aos demais ânions analisados, o que demonstra sua importância em sol os tiomórficos, como já havia sido constatado por Seiler (1992). Os altos níveis de sulfato podem ocasionar sérios problemas em relação a outros ânions importantes à nutrição mineral de plantas, como o fosfato e o nitrato (Rorison, 1973).

O comportamento dos cátions solúveis, determinados nas amostras úmidas e secas ao ar, foi semelhante ao apresentado pelos cátions trocáveis nos perfis estudados, ou seja, o magnésio foi o cátion dominante, seguido do cálcio, sódio e potássio (Quadro 5). Observou-se, ainda, que as determinações realizadas nas amostras secas apresentaram val ores superiores às realizadas com as amostras úmidas. Essa diferença pode também ser atribuída às alterações causadas pelo processo de sulfurização, acelerado pela secagem das amostras.

Em relação ao balanço de cátions e ânions, observou-se um desequilíbrio que, de forma geral, mostrou-se mais pronunciado nos horizontes sulfúricos para as amostras secas ao ar. Nestes horizontes, ocorreram, quase sempre, maiores concentrações de ânions na forma do íon sulfato. $\mathrm{O}$ grande desequilíbrio de ânions nos horizontes sulfúricos vem demonstrar a grande partici pação do íon $\mathrm{H}^{+}$, sugerindo que a alta condutividade el étrica não indica exclusivamente a presença de sais solúveis, mas, sim, de ácido sulfúrico formado pelo processo de sulfurização, como discutido anteriormente.

\section{Manejo dos solos tiomórficos}

No quadro 6, são apresentados as dosagens de carbonato de cál cio aplicadas aos sol os e os val ores de $\mathrm{pH}$ em água, $\mathrm{H}+\mathrm{Al}$ e $\mathrm{Al}^{3+}$ aos 60 dias de incubação. A neutralização do $\mathrm{H}+\mathrm{Al}$ foi atingida, em ambos os solos e em ambas as profundidades, 
Quadro 4. Condutividade elétrica, pH e ânions solúveis determi nados no extrato da pasta de saturação em terra fina seca ao ar (TFSA) e em amostras com umidade de campo (ACUC) dos solos

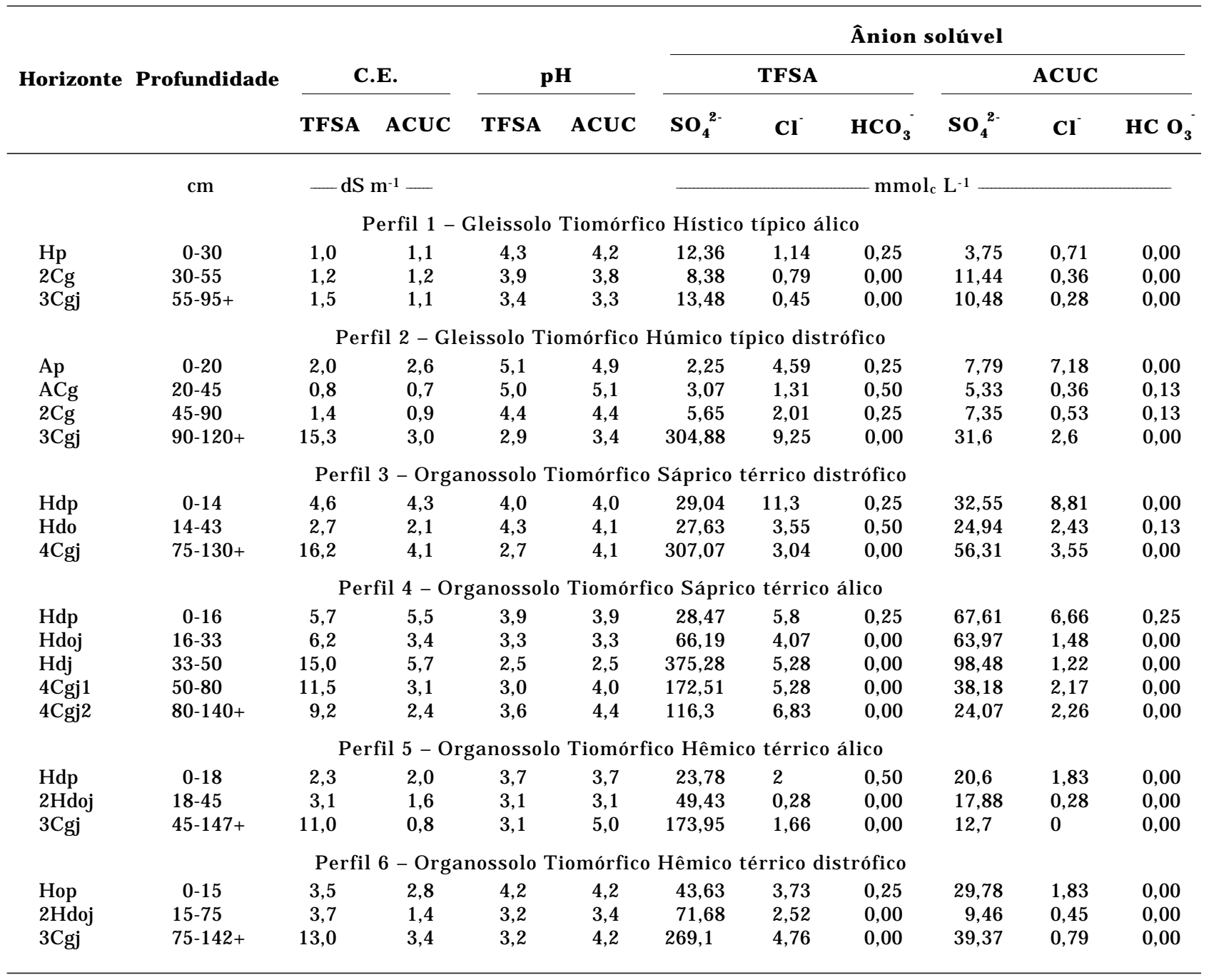

com dosagens do corretivo superiores a $50 \mathrm{t} \mathrm{ha}^{-1}$, exceto na profundidade de $20-40 \mathrm{~cm}$ do Organossolo, onde este valor ficou próximo a $40 \mathrm{t} \mathrm{ha}^{-1}$. Vale ressaltar que não é necessário atingir este nível de correção, porque o pH neste ponto é superior a 7,0, podendo ocasionar problemas nutricionais às plantas, principal mente em relaçãoà disponibilidade de micronutrientes, e antagonismo entre o cálcio e magnésio em relação ao potássio.

Do experimento realizado, pode-se observar que as necessidades de corretivo entre os solos foram bem distintas. O Gleissolo, para atingir $\mathrm{pH}$ na faixa de 5,4 a 5,7, necessitou de dosagens de calcário de $25 \mathrm{t} \mathrm{ha}^{-1}$, em ambas as profundidades. Já os Organossol os requereram 16 e 11 t ha-1, para as $^{-1}$ profundidades de 0-20 e 20-40 cm, respectivamente. Estefato deveu-se aos maiores teores deAl ${ }^{3+}$ trocável nos Gleissol os (Pavan \& Miyazawa, 1997).
Verificou-se que, aos 15 dias, o pH nos dois solos e em ambas as profundidades foi bruscamenteelevado, atingindo valores bem próximos aos observados aos 60 dias da realização do experimento (Quadro 6).

Considerando a tolerância de algumas culturas tropicais a níveis elevados de acidez, ouso de grandes quantidades de cal cário para atingir valores de $\mathrm{pH}$ acima de 4,5 pode não ser necessário. $\mathrm{E} m$ estudos real izados em solos tiomórficos na Malásia, verificouse que as culturas de coco, abacaxi, café e dendê podem ser desenvol vidas em sol os com $\mathrm{pH}$ em torno de 4,0 (Kanapathy, 1973). Da mesma forma, foi observado um bom desenvolvimento da cultura da cana-de-açúcar em sol os orgânicos tiomórficos com pH em torno de 4,0 (Usina Coruripe, 1997).

Segundo Andriesse (1984), em sol os de natureza orgânica, parte do alumínio pode estar complexada 
Quadro 5. Cátions solúveis no extrato da pasta saturada determinados em terra fina seca ao ar (TF SA) e em amostras com umidade de campo (ACUC)

\begin{tabular}{|c|c|c|c|c|c|c|c|c|c|c|c|}
\hline \multirow{2}{*}{\multicolumn{2}{|c|}{ Horizonte Profundidade }} & \multicolumn{5}{|c|}{ TFSA } & \multicolumn{5}{|c|}{ ACUC } \\
\hline & & $\mathrm{Ca}^{2+}$ & $\mathbf{M g}^{2+}$ & $\mathbf{K}^{+}$ & $\mathrm{Na}^{+}$ & Soma & $\mathrm{Ca}^{2+}$ & $\mathbf{M g}^{2+}$ & $\mathbf{K}^{+}$ & $\mathrm{Na}^{+}$ & Soma \\
\hline & $\mathrm{cm}$ & & & & & & & & & & \\
\hline \multicolumn{12}{|c|}{ Perfil 1 - Gleissolo Tiomórfico Hístico típico álico } \\
\hline $\mathrm{Hp}$ & $0-30$ & 4,48 & 3,97 & 0,08 & 2,04 & 10,56 & 5,14 & 4,24 & 0,05 & 1,73 & 11,17 \\
\hline $2 \mathrm{Cg}$ & $30-55$ & 4,32 & 4,94 & 0,07 & 1,89 & 11,23 & 4,06 & 4,45 & 0,04 & 1,58 & 10,14 \\
\hline 3Cgj & $55-95+$ & 3,42 & 4,4 & 0,40 & 1,95 & 10,18 & 2,38 & 3,37 & 0,19 & 1,14 & 7,08 \\
\hline \multicolumn{12}{|c|}{ Perfil 2 - Gleissolo Tiomórfico Húmico típico distrófico } \\
\hline Ap & $0-20$ & 7,21 & 8,53 & 0,13 & 3,49 & 19,37 & 10,07 & 11,85 & 0,16 & 6,21 & 28,29 \\
\hline $\mathrm{ACg}$ & $20-45$ & 2,7 & 2,89 & 0,03 & 2,72 & 8,34 & 2,31 & 2,41 & 0,03 & 2,38 & 7,13 \\
\hline $2 \mathrm{Cg}$ & $45-90$ & 4,21 & 4,5 & 0,17 & 4,46 & 13,34 & 2,87 & 3,05 & 0,12 & 3,76 & 9,80 \\
\hline 3Cgj & $90-120+$ & 20,26 & 171 & 0,06 & 27,67 & 219,02 & 8,22 & 17,97 & 0,76 & 10,08 & 37,03 \\
\hline \multicolumn{12}{|c|}{ Perfil 3 - Organossolo Tiomórfico Sáprico térrico distrófico } \\
\hline $\mathrm{Hdp}$ & $0-14$ & 20,18 & 29,13 & 0,37 & 6,47 & 56,14 & 18,95 & 24,88 & 0,37 & 5,90 & 50,10 \\
\hline Hdo & $14-43$ & 12,12 & 16,43 & 0,14 & 4,61 & 33,30 & 9,81 & 13,99 & 0,08 & 3,59 & 27,47 \\
\hline 4Cgj & $75-130+$ & 18,18 & 202,5 & 0,04 & 21,08 & 241,83 & 12,81 & 29,7 & 0,48 & 10,99 & 53,99 \\
\hline \multicolumn{12}{|c|}{ Perfil 4 - Organossolo Tiomórfico Sáprico térrico álico } \\
\hline $\mathrm{Hdp}$ & $0-16$ & 25,69 & 65,79 & 0,77 & 10,40 & 102,65 & 25,37 & 36,2 & 0,74 & 10,53 & 72,83 \\
\hline H doj & $16-33$ & 18,01 & 41,88 & 1,05 & 8,41 & 69,35 & 8,49 & 14,78 & 0,41 & 3,90 & 27,58 \\
\hline $\mathrm{Hdj}$ & $33-50$ & 6,19 & 88,25 & 0,41 & 15,96 & 110,80 & 7,8 & 22,26 & 0,11 & 4,78 & 34,95 \\
\hline 4Cgj 1 & $50-80$ & 20,09 & 129,1 & 0,94 & 17,18 & 167,30 & 6,04 & 17,86 & 1,77 & 7,31 & 32,98 \\
\hline $4 \mathrm{Cgj} 2$ & $80-140+$ & 21,67 & 107,4 & 1,84 & 22,21 & 153,11 & 4,15 & 14,63 & 1,16 & 8,73 & 28,67 \\
\hline \multicolumn{12}{|c|}{ Perfil 5 - Organossolo Tiomórfico Hêmico térrico álico } \\
\hline $\mathrm{Hdp}$ & $0-18$ & 5,71 & 9,16 & 0,48 & 5,48 & 20,83 & 5,65 & 7,99 & 0,29 & 5,78 & 19,72 \\
\hline $2 \mathrm{H}$ doj & $18-45$ & 6,94 & 11,07 & 0,86 & 3,27 & 22,14 & 3,12 & 4,12 & 0,36 & 1,50 & 9,10 \\
\hline $3 \mathrm{Cgj}$ & $45-147+$ & 22,88 & 147,7 & 0,18 & 14,93 & 185,66 & 0,86 & 1,5 & 0,20 & 4,43 & 6,99 \\
\hline \multicolumn{12}{|c|}{ Perfil 6 - Organossolo Tiomórfico Hêmico térrico distrófico } \\
\hline Hop & $0-15$ & 21,43 & 18,4 & 0,21 & 6,49 & 46,53 & 16,22 & 13,28 & 0,12 & 6,19 & 35,81 \\
\hline $2 \mathrm{H}$ doj & $15-75$ & 14,6 & 17,11 & 0,85 & 4,90 & 37,46 & 4,66 & 4,32 & 0,16 & 2,03 & 11,17 \\
\hline $3 \mathrm{Cgj}$ & $75-142+$ & 21,58 & 181,5 & 1,17 & 24,53 & 228,72 & 9,36 & 26,92 & 1,19 & 8,30 & 45,77 \\
\hline
\end{tabular}

pela matéria orgânica deforma bastante estável, não causando, assim, maiores problemas de toxidez às culturas, mesmo estando em altos teores e em condições de acidez el evada. Considerando esta afirmação, é de fundamental importância que se mantenha o nível elevado da matéria orgânica desses solos, porque, caso o ambiente torne-se propício à mineralização intensa, o alumínio até então complexado passaria a estar solúvel às plantas, impedindo, assim, o seu desenvol vimento e produção normal.

Apesar da possi bilidade da utilização de corretivos no controle da acidez dos sol os tiomórficos, é por meio do manejo do regime hídrico que se pode atingir o uso agrícola sustentável desses solos. O manejo do regime hídrico pode ser feito pelo controle do nível do lençol freático por um sistema de drenagem por bombeamento, como o atualmente encontrado na área do estudo.
Esta prática promoverá um controle de grande importância em se tratando de solos tiomórficos, que éa redução da oxidação da pirita. Um nível el evado de umi dade restringe a entrada de oxigênio no solo e, assim, o desenvol vimento do horizonte sulfúricoé impedido, resultando em menor acidez e menores níveis de alumínio trocável. Com esta prática também são control ados problemas de desidratação irreversível dos horizontes orgânicos ea subsidência.

\section{CONCLUSÕES}

1. O maior desenvolvimento de horizonte sulfúrico nos sol os com mais al tos teores de matéria orgânica veio confirmar a importância de substâncias orgânicas na formação dos solos tiomórficos. 
Quadro 6. Efeito da quantidade de corretivo nos teores de $\mathrm{H}+\mathrm{Al}, \mathrm{Al}^{3+} \mathrm{e}^{+}$trocáveis, após 60 dias de incubação, e comportamento do pH durante o período de 60 dias

\begin{tabular}{|c|c|c|c|c|c|c|c|}
\hline \multirow{3}{*}{$\begin{array}{l}\text { Quantidade } \\
\text { de corretivo }\end{array}$} & \multirow{2}{*}{\multicolumn{2}{|c|}{ Após 60 dias de incubação }} & \multicolumn{5}{|c|}{ pH } \\
\hline & & & \multicolumn{5}{|c|}{ Dias de incubação } \\
\hline & $\mathbf{H}+\mathbf{A l}$ & $\mathrm{Al}^{3+}$ & $\mathbf{0}$ & 15 & 30 & 45 & 60 \\
\hline t ha $^{-1}$ & \multicolumn{2}{|c|}{$\mathrm{cmol}_{\mathrm{c}} \mathrm{kg}^{-1}$} & & & & & \\
\hline \multicolumn{8}{|c|}{ Perfil 1 - Gleissolo Tiomórfico Hístico típico 0-20cm } \\
\hline 0 & 27,2 & 12,2 & 3,9 & 3,9 & 3,7 & 3,4 & 3,6 \\
\hline 6,38 & 21,9 & 6,8 & 3,9 & 4,5 & 4,3 & 4,0 & 4,1 \\
\hline 12,76 & 17,0 & 2,2 & 3,9 & 5,1 & 4,8 & 4,5 & 4,6 \\
\hline 25,52 & 9,1 & 0,2 & 3,9 & 6,1 & 6,1 & 5,7 & 5,7 \\
\hline 51,04 & 0,2 & 0,0 & 3,9 & 7,9 & 8,0 & 7,7 & 7,5 \\
\hline \multicolumn{8}{|c|}{ Perfil 1 - Gleissolo Tiomórfico Hístico típico 20-40cm } \\
\hline 0 & 29,1 & 12,9 & 3,8 & 3,8 & 3,7 & 3,3 & 3,6 \\
\hline 6,41 & 23,0 & 6,8 & 3,8 & 4,4 & 4,2 & 3,9 & 4,1 \\
\hline 12,81 & 17,7 & 2,2 & 3,8 & 4,9 & 4,8 & 4,4 & 4,6 \\
\hline 25,82 & 10,2 & 0,2 & 3,8 & 6,0 & 6,0 & 5,5 & 5,7 \\
\hline 51,24 & 0,1 & 0,0 & 3,8 & 7,8 & 8,0 & 7,9 & 7,7 \\
\hline \multicolumn{8}{|c|}{ Perfil 6 - Organossolo Tiomórfico Hêmico térrico 0-20 cm } \\
\hline 0 & 44,3 & 6,5 & 4,3 & 4,5 & 4,3 & 3,9 & 4,1 \\
\hline 8,33 & 32,8 & 1,1 & 4,3 & 5,2 & 5,0 & 4,7 & 4,8 \\
\hline 16,66 & 20,9 & 0,2 & 4,3 & 5,8 & 5,6 & 5,4 & 5,5 \\
\hline 33,31 & 9,0 & 0,0 & 4,3 & 6,7 & 6,6 & 6,4 & 6,4 \\
\hline 66,62 & 0,1 & 0,0 & 4,3 & 8,1 & 8,1 & 8,0 & 7,8 \\
\hline \multicolumn{8}{|c|}{ Perfil 6 - Organossolo Tiomórfico Hêmico térrico $20-40$ cm } \\
\hline 0 & 76,1 & 8,8 & 3,7 & 3,9 & 3,6 & 3,3 & 3,5 \\
\hline 11,22 & 27,3 & 0,2 & 3,7 & 5,6 & 5,5 & 5,4 & 5,4 \\
\hline 22,43 & 11,5 & 0,1 & 3,7 & 6,8 & 6,8 & 6,6 & 6,5 \\
\hline 44,86 & 0,1 & 0,0 & 3,7 & 7,9 & 8,2 & 8,1 & 7,9 \\
\hline 89,72 & 0,0 & 0,0 & 3,7 & 8,2 & 8,4 & 8,4 & 8,1 \\
\hline
\end{tabular}

2. O processo de secagem das amostras em laboratório promoveu a oxidação dos sulfetos e a formação de ácido sulfúrico, alterando as condições naturais dos solos no campo.

3. A alta condutividade elétrica encontrada em solos tiomórficos nãoé, necessariamente, indicativo de salinidade, podendo estar relacionada com a formação de ácido sulfúrico gerado pela oxidação de sulfetos no processo de sulfurização.

4. Os solos tiomórficos apresentaram características químicas muito peculiares, requerendo novos estudos para métodos de amostragem e análises, específicos a estes solos.

5. Para correção do alumínio trocável dos horizontes superficiais dos solos estudados, foram necessárias doses de 11 a 25 t ha-1 de carbonato de cálcio.

6. A manutenção do solo úmi do pelo controle do sistema de drenagem, mantendo olençol freático em torno de $30 \mathrm{~cm}$ de profundidade, é a forma mais eficiente esustentável de controle da acidez dos solos tiomórficos, sendoindispensável à utilização agrícola dos solos com a cultura da cana-de-açúcar.

\section{LITERATURA CITADA}

ADRIANO, D.C. \& DONER, H.E. Bromine, chlorineand Fluorine. In: PAGE, A.L.; MILLER, R.H. \& KEENEY, D.R., eds. Methods of soil analysis: chemical and microbiological properties. 2.ed. Part 2. Madison, American Society of Agronomy - Soil Science Society of America, 1982. p.449483.

ALVES, E.A.B. Solos orgânicos salinos tiomórficos: Influência da calagem, sob drenagem controlada, nas características químicas do solo e na produção e composição mineral de Brachiária decumbens, Panicum repens L. ecana-de-açúcar. Campos dos Goytacazes, Universidade Estadual do Norte Fluminense, 1997. 82p. (Tese de Mestrado) 
ANDRIESSE, J. U so de solos orgânicos em condições tropicais e subtropicais aliado às possibilidades brasileiras. In: SIMPÓSIO NACIONAL DE SOLOS ORGÂNICOS, Curitiba, 1984. Anais. Curitiba, 1984. p.11-33.

BRADY, N.C. Solos orgânicos (Histosols). Sua natureza, propriedades e utilização. In: Natureza e propriedades dos solos. 7ed. Rio de J aneiro, Freitas Bastos, 1989. 554p.

CONCEIÇÃO, M. Natureza do humus e caracterização de solos com elevado teor de matéria orgânica da região de I taguaíSanta Cruz, RJ . Rio dejaneiro, U niversidade Federal Rural do Rio de J aneiro, 1989. 169p. (Tese de Mestrado)

DENT, D. Acid sulphate soils: a baseline for research and devel opment. Wageningen, I nternational I nstitute for Land Reclamation and I mprovement, 1986. 203p. (Public, 39)

DEWIS, J . \& FREITAS, F. Physical and chemical methods of soil and water analysis. Rome, Food and Agriculture Organization of the United nations, 1970. p.233-238. (Soils Bulletin, 10)

EMPRESA BRASILEIRA DE PESQUISA AGROPECUÁRIA EMBRAPA. Centro Nacional de Pesquisa de Solos. Manual de métodos de análises de Solo. Rio de J aneiro, 1997. 212p (Embrapa-CNPS, 1)

EMPRESA BRASILEIRA DE PESQUISA AGROPECUÁRIA EMBRAPA. Serviço de Produção de I nformação - SPI. Sistema Brasileiro de Classificação de Solo. Brasília, 1999. 412p.

KANAPATHY, K. Reclamation and improvement of acid sul phate soils in West Malaysia. In: DOST, H., ed. Acid sulphate soils. Wageningen, I nternational I nstitute for Land Redamation and I mprovement, 1973. v.1. p.383-390.

LANI, J .L. Deltas dos Rios Doce e I tapemirim: Solos, com ênfase nos tiomórficos, água e impacto ambiental do uso. Viçosa, Universidade Federal de Viçosa, 1998. 169p. (Tese de Doutorado)
LEMOS, R.C. \& SANTOS, R.D. Manual de descrição e coleta de solo no campo. 2ed. Campinas, Sociedade Brasileira de Ciência do Solo, 1996. 84p.

MALAVOLTA, E. Elementos de nutrição de plantas. São Paulo, Ceres, 1980. 251p.

MALAVOLTA, E. ABC da análise de sol os e fol has: amostragem, interpretação e sugestão de adubação. São Paulo, Ceres, 1992. $124 p$.

OLIVEIRA,J .B.;] ACOMINE, P.K.T. \& CAMARGO, M.N. Classes gerais de solos do Brasil: guia auxiliar para seu reconhecimento. J aboticabal, Fundação de Estudos e Pesquisas em Agronomia, Medicina Veterinária eZootecnia, 1992. 201p.

PAVAN, M.A. \& MIYAZAWA, M. Lições de fertilidade do solo pH. Londrina, Instituto Agronômico do Paraná, 1997. 47p. (Circular, 93)

RAIJ , B. van. Fertilidade do solo e adubação. Piracicaba, Ceres, 1991. 343p.

RORISON, I.H. The effect of extreme soil acidity on the nutrient uptake and physiology of plants. In: DOST, H., ed. Acid sulphatesoils. Wageningen, I nternational Institute for Land Reclamation and I mprovement, 1973. v.1. p.223-251.

SEILER, E. Acid sulphate soils - Their formation and agricultural use. Hannover, Institute for Scientic Co-operation, 1992. p.92-110. (Natural Resources and Development, 35)

SNYDER, J.D. \& TROFYNOW, J.A. A rapid accurate wet oxidation diffusion procedure for determing organic and inorganic carbon in plant and soil samples. Soil Sci. Plant Anal., 15:587-597, 1984.

SOUZA J r., V.S. Caracterização, gênese e manejo de solos tiomórficos da várzea do rio Coruripe, estado de Alagoas. Recife, Universidade Federal Rural de Pernambuco, 1999. 92p.(Tese de Mestrado)

USINA CORURIPE. Levantamento detal hado de sol os (Várzeas) da Usina Coruripe. Coruripe, 1997. 45p. (não plubicado) 